Article - Human and Animal Health

\title{
Anti-inflammatory Effect of a Goji Berry Extract (Lycium barbarum) in Rats Subjected to Inflammation by Lipopolysaccharides (LPS)
}

\author{
Caroline Nickel Ávila ${ }^{1}$ \\ https://orcid.org/0000-0001-9124-7575
}

\section{Fernanda Moura Ribeiro Trindade ${ }^{2}$}

https://orcid.org/0000-0001-8777-8314

Júlia Oliveira Penteado ${ }^{3}$

https://orcid.org/0000-0002-4843-8971

\section{Fernanda Janke ${ }^{2}$}

https://orcid.org/0000-0002-3436-4967

Janaína Pereira Schneider ${ }^{2}$

https://orcid.org/0000-0003-3371-4926
Júlia Neitzel Uecker ${ }^{2}$

https://orcid.org/0000-0003-0467-4056

Joao Alveiro Alvarado Rincón 4

https://orcid.org/0000-0002-1413-5120

Carlos Castilho de Barros ${ }^{2}$

https://orcid.org/0000-0002-6926-734X

Robson Andreazza ${ }^{5}$

https://orcid.org/0000-0001-9211-9903

Simone Pieniz ${ }^{2^{\star}}$

https://orcid.org/0000-0002-7403-1577

${ }^{1}$ Catholic University of Pelotas, Postgraduate Program in Health and Behavior, Pelotas, Rio Grande do Sul, Brazil; ${ }^{2}$ Federal University of Pelotas, College of Nutrition, Department of Nutrition, Pelotas, Rio Grande do Sul, Brazil; ${ }^{3}$ Federal University of Rio Grande, Postgraduate Program in Health Sciences, Rio Grande, Rio Grande do Sul, Brazil; ${ }^{4}$ Federal University of Pelotas, Postgraduate Program in Veterinary, Pelotas, Rio Grande do Sul, Brazil; ${ }^{5}$ Federal University of Pelotas, Engineering Center, Pelotas, Rio Grande do Sul, Brazil.

Received: 2018.10.31; Accepted: 2020.03.19.

${ }^{*}$ Correspondence: nutrisimone@yahoo.com.br; Tel.: +5553 3284 3831; Fax: +5553 32843830 (F.L.)

\section{HIGHLIGHTS}

- Lycium barbarum extract displays the potential to reduce inflammatory responses.

- L. barbarum promotes the reduction of the inflammatory response in the palatable diet.

- L. barbarum reduced glutamic-oxaloacetic transaminase activity in the both diets.

- L. barbarum increase the expression of TNF- $\alpha$ and IL-6 genes in the standard diet.

Abstract: The present study aimed to evaluate the anti-inflammatory potential of a $L y c i u m$ barbarum $(L$. barbarum) fruit extract in Wistar rats submitted to a palatable diet presenting systemic inflammation induced by lipopolysaccharides (LPS). Forty-two Wistar female rats (Rattus Novergicus) were used with 60 days old. The animals were feed for 60 days and divided in six groups $(n=7)$ : standard diet+water; standard diet $+L$. barbarum; palatable diet+water; palatable diet+L. barbarum; standard diet+water+LPS; standard diet $+L$. barbarum+LPS. A significant difference was shown between the analyzed groups concerning C-reactive protein, with the standard diet+water+LPS group presenting the highest inflammatory response in comparison to the other groups. Decreased inflammatory response was observed in the group administered a palatable diet along with the fruit extract when compared to the group that received only a palatable diet. Significant decrease in glutamic-oxaloacetic transaminase activity was observed in the standard diet $+L$. barbarum+LPS group compared to the standard diet+water group, as well as in the palatable diet $+L$. 
barbarum group compared to the palatable diet+water group. A significant increase in creatinine in the standard diet+water+LPS group was observed in according to the L. barbarum administration groups. The gene expression of the inflammatory markers genes in the liver showed a significant increase in TNF- $\alpha$ and IL-6 genes in the group treated with standard diet+L. barbarum+LPS when compared to the standard diet+LPS group. Thus, the administered $L$. barbarum extract displays the potential to reduce inflammatory responses induced by LPS and a palatable diet.

Keywords: systemic inflammation; palatable die; proinflammatory cytokines.

\section{INTRODUCTION}

Systemic inflammatory responses can be triggered by infectious and non-infectious factors, but the most applied research models use lipopolysaccharides (LPS), an outer membrane component of gram-negative bacteria and an important microbial trigger that stimulates innate immunity [1]. Once LPS comes into contact with the animal organism, excessive production of proinflammatory cytokines occurs, including tumor necrosis factor (TNF- $\alpha$ ) and interleukins (IL) - $1 \mathrm{~b}, \mathrm{IL}-6$ and IL- 8 by immunocompetent cells, which may induce inflammatory responses [2]. LPS may also act on monocytes, neutrophils, blood platelets and endothelial cells, and, especially, macrophages [3].

TNF- $\alpha$ was discovered by Carswell and coauthors [4] in 1975, and is considered one of the main cytokines related to inflammatory and immune processes, produced by the immune system and acting in different parts of the body. It is produced and secreted by macrophages, lymphocytes and monocytes in response to certain toxic-infectious stimuli $[5,6]$, and the presence of bacterial LPS is the main stimulus for the installation of the inflammatory process. Serum TNF- $\alpha$ levels become elevated in some disease states, such as septic shock, graft rejection, HIV infection, neurodegenerative diseases, rheumatoid arthritis and cancer [7], and this cytokine is also involved in the pathogenesis of chronic inflammation in both rat and human models [8]. Thus, the main physiological effect of TNF- $\alpha$ is to promote immune and inflammatory responses.

IL-6 is a classical pro-inflammatory cytokine produced by a variety of cells, such as T lymphocytes, B lymphocytes, fibroblasts, monocytes, keratinocytes, endothelial cells and various tumor cells [9]. It plays a central role in the regulation of inflammatory and immune responses. Its release is stimulated by acute infections, chronic inflammatory conditions, obesity and physiological stress [10]. IL-6 is involved not only in the activation of the immune system but also in regenerative processes, as well as in metabolism regulation, maintenance of bone homeostasis and many neural functions [11].

The determination of C-reactive protein has also been extensively applied in the diagnosis of inflammatory and infectious conditions. This protein is an acute phase protein produced by the liver as part of systemic inflammatory responses [12], and its production occurs in response to stimulation by inflammatory cytokines. The determination of C-reactive protein is useful in the diagnosis and monitoring of many acute and chronic inflammatory diseases, including infections, periodontal disease, chronic lung disease, obesity, and metabolic syndrome [13].

Similarly, haptoglobin ( $\mathrm{Hp})$ has also been used as an inflammatory process parameter. Haptoglobin belongs to a family of acute phase serum glycoproteins, induced by the secretion of IL-6, IL-1 and TNF- $\alpha$. It is primarily generated by liver hepatocytes and by skin, kidneys and lungs, in small amounts [14]. It is also found in immune cells, including neutrophils and monocytes [15]. Under normal physiological conditions, it is absent or present at very low levels. However, haptoglobin may increase significantly in response to acute infection, inflammation or trauma [14].

Diet is known to play an important and significant role in the regulation of chronic inflammation. In this context, C-reactive protein and inflammatory cytokines, such as IL-6 and TNF- $\alpha$, are increased in obese individuals, correlating positively with Body Mass Index (BMI) and central adiposity, which is, in turn, associated to increased inflammation [16], with obesity seen as a low intensity inflammatory state. Ingestion of food in general, especially foods high in carbohydrates (mainly sucrose) and lipids, and, particularly, excessive food intake, generates oxidative stress, which in turn stimulates inflammation mediators [17].

Extract of plants demonstrating anti-inflammatory and antioxidant properties have been used in several studies [18]. The fruit Lycium barbarum (L. barbarum) is noteworthy in this scenario, as it has been used as an anti-inflammatory and antipyretic agent in traditional Chinese medicine [19] and widely marketed as a health food and anti-aging and anti-oxidant drug substance in Western countries [20]. Studies have reported that $L$. barbarum possesses several biological activities, playing an important role in the prevention and treatment of various chronic diseases such as diabetes, hyperlipidemia, hypoglycemia, metabolic syndrome, cancer, hepatitis, hypofunction-immunity, thrombosis and male infertility, and also used for renal protection 
$[20,21,22]$. In this context, this study aimed to evaluate the anti-inflammatory response of a $L$. barbarum fruit extract in female Wistar rats submitted to a hyperpalatable diet presenting systemic LPS-induced inflammation.

\section{MATERIAL AND METHODS}

\section{Sample characterization}

L. barbarum fruits were bought at the Pelotas Public Market, RS, Brazil, obtained from China as dried fruits. The fruits were sampled in bulk, placed in hermetically closed jars and taken to the Laboratory of Experimental Nutrition, at the Nutrition School of the Federal University of Pelotas (UFPEL).

\section{Conditions and experimental model}

This study was approved by the Ethics Committee on Animal Experimentation (UFPEL), under registration number 9662-2015. Forty-two female Wistar rats (Rattus novergicus), 60 days old, obtained from the UFPEL Central Animal Laboratory were used. The animals were maintained in polypropylene boxes in ventilated cabinets, with controlled temperature and relative humidity conditions $\left(23^{\circ} \mathrm{C} \pm 1^{\circ} \mathrm{C}\right.$ and $\left.65-75 \%\right)$, under a 12-hour light/dark cycle. After five days of adaptation, the animals were randomly divided into six groups, comprising seven animals each, namely SW: standard diet + water; SL: standard diet + L. barbarum; PW: palatable diet + water; PL: palatable diet + L. barbarum; SWL: standard diet + water + LPS; SLL: standard diet + L. barbarum + LPS. The palatable diet was composed of $25 \%$ standard diet, $34 \%$ condensed milk, 23\% corn starch, $8 \%$ sucrose and 10\% lipid content (soybean oil) [23]. L. barbarum extracts were prepared daily at a $20 \%$ concentration $(\mathrm{v} / \mathrm{v})$ using water at room temperature, and applied by gavage $(2 \mathrm{~mL}-$ 1 of extract per day per animal). LPS was administered 6 hours prior to euthanasia, in the standard diet + LPS and standard diet + L. barbarum + LPS groups, at $500 \mu \mathrm{g} \mathrm{Kg}^{-1}$ animal weight, with body temperature measured every 30 minutes with commercial digital thermometer. After 60 days, the animals were fasted for three hours and sedated with isoflurane (Isoflurano, BioChimico, Rio de Janeiro, Brazil). They were euthanized by cardiac puncture, in accordance with Resolution Protocol no 714 of June 2002 of the Federal Council of Veterinary Medicine, following the Ethical Principles in Animal Experimentation adopted by the Brazilian College of Animal Experimentation.

\section{Blood collection and storage}

Blood was collected at moment of rat decapitation in tubes both containing and not containing ethylenediamine tetraacetic acid (EDTA) and centrifuged at 3,500 rpm for 10 minutes (Centrifuge 5415, Eppendorf, Westbury, New York, USA). The serum was then transferred to eppendorfs and stored at $-80^{\circ} \mathrm{C}$ until analysis.

\section{C-reactive protein quantification}

Plasma C-reactive protein (CRP) was determined by the Ultra-Sensitive-Turbidimetric CRP method using a TARGA 3000 biochemical analyzer (Random Access Chemistry Analyzer Biotechnology Instruments). Briefly, the samples were treated with a specific antibody to rat CRP in a suitable buffer. The turbidity induced by the formation of immune complexes was measured at $546 \mathrm{~nm}$, and the values were then calculated automatically from a known standard. All the assay steps were performed automatically by the instrument. A commercial control serum was used to verify the assay performance. Abnormality cutoff points, previously mentioned in the literature [24], comprised values over $3 \mathrm{mg} \mathrm{L}^{-1}$.

\section{Haptoglobin determination}

Plasma haptoglobin determination was performed according to the guaiacol method described by Jones and Mould [25]. A standard curve was developed with standard haptoglobin solutions diluted from 0.56 to $0.01 \mathrm{~g} \mathrm{~L}^{-1}$. Fifty microliter $(50 \mu \mathrm{L})$ of haptoglobin standard or plasma sample was added to $50 \mu \mathrm{L}$ of $0.9 \%$ saline solution in each well. Next, $50 \mu \mathrm{L}$ of rats methemoglobin solution (30 mg dL $\left.\mathrm{d}^{-1}\right)$ was added and plates were incubated for $10 \mathrm{~min}$ at $20^{\circ} \mathrm{C}$. A blank (50 $\mu \mathrm{L}$ of $0.9 \%$ saline) was run with each serum sample. Following incubation, a guaiacol reagent $(150 \mu \mathrm{L}, \mathrm{pH} 4.0)$ and $50 \mu \mathrm{L}$ of $\mathrm{H}_{2} \mathrm{O}_{2}$ solution $\left(0.02 \mathrm{~mol} \mathrm{~L}^{-1}\right)$ were added. After $10 \mathrm{~min}$, absorbance at $490 \mathrm{~nm}$ was measured using a microplate reader. All samples were run in duplicate and the mean of each duplicate was used to calculate the final concentration based on the standard curve. 


\section{Determination of glutamic-oxaloacetic transaminase and glutamic-pyruvic transaminase enzymes}

Serum transaminases (glutamic-oxaloacetic transaminase (GOT) and glutamic-pyruvic transaminase (GPT)) were performed by a colorimetric method using a commercial kit (Doles®, Goiânia - GO, Brazil). Readings were obtained spectrophotometrically at $505 \mathrm{~nm}$ and the results were expressed as IU/L, using previously published data as reference $(\mathrm{GOT}=67.67 \mathrm{IU} / \mathrm{L}$ and $\mathrm{GPT}=27.56 \mathrm{IU} / \mathrm{L})$ [26].

\section{Determination of creatinine concentrations}

Serum creatinine was determined using commercial kits (Creatinine $K \circledast$, Labtest Diagnostica SA, Lagoa Santa, Brazil) based on the Jaffé reaction. Briefly, $50 \mathrm{uL}$ of serum sample was mixed with $50 \mathrm{uL}$ of alkaline picrate and readings were obtained spectrophotometrically at $520 \mathrm{~nm}$ after 0 and 60 seconds. Results were expressed as $\mathrm{mg} \mathrm{dL}^{-1}$, using previously published data as reference $\left(0.96 \mathrm{mg} \mathrm{dL}^{-1}\right)$ [26].

\section{Gene expression determination of oxidative stress- related enzymes}

To determine gene expression, liver samples were obtained and immediately stored at $-80 \mathrm{oC}$. The samples were subsequently homogenized with Qiazol (Qiagen, Valencia, USA), and total RNA was isolated

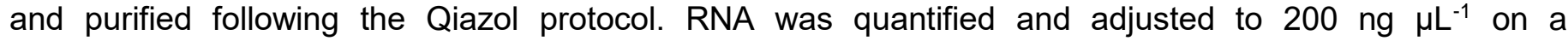
spectrophotometer (Nanodrop Lite, Thermo Fischer Scientific Inc., USA) applying the 260/280 nm absorbance ratio. RNA quality was assessed by electrophoresis on agarose gels. Reverse transcription reactions were performed using $1 \mu \mathrm{g}$ of RNA with a reverse transcription kit containing RNase inhibitor (Applied Biosystems, Foster City, USA) in $10 \mu \mathrm{L}$. Real-time PCR was performed to assess the expression of the target genes inflammatory markers tumor necrosis factor alpha (TNF- $\alpha$ ) and interleukin 6 (IL-6) using beta-actin (Actb) as the internal control (Table 1).

PCR reactions were performed in triplicate with $12 \mu \mathrm{L}$ of each sample using a SYBR Green Mastermix (Applied Biosystems) and fluorescence was quantified on an Eco Real Time (Illumina, San Diego, California, USA). For each test, 40 cycles $\left(95^{\circ} \mathrm{C}\right.$ for 10 seconds and $60^{\circ} \mathrm{C}$ for 30 seconds) were carried out and a dissociation curve was included at the end of the reaction, in order to verify the amplification of a single PCR product. The coefficient of variation was less than $3 \%$ for all the pairs of primers used. Relative expression was calculated as $2 A-B / 2 C-D$, according to Masternak and coauthors [27]. Each assay plate included a negative control comprising water.

\section{Statistical analyses}

Data were statistically tested by an analysis of variance (ANOVA) and Tukey test, at a $5 \%$ of significance level, in order to compare data means, using the Graph Pad Prism software, version 6.0. Likewise, gene expression was evaluated after normalization of the target gene expressions by beta-actin applying the oneway ANOVA using the Graph Pad Prism 6.0 software.

\section{RESULTS}

\section{Body temperature}

LPS was used as an inflammation inducer. A $35.79 \pm 0.44{ }^{\circ} \mathrm{C}$ increase in body temperature in the standard diet + water group (control) to $37.84 \pm 0.11^{\circ} \mathrm{C}$ in the LPS (SWL) group was observed, while a significant decrease $(\mathrm{p}<0.05)$ in temperature $\left(36.09 \pm 0.66^{\circ} \mathrm{C}\right)$ was detected after $L$. barbarum extract administration (Figure 1).

\section{C-reactive protein}

C-reactive protein values are displayed in Figure 2. A significant difference $(p \leq 0.01)$ was observed between the analyzed groups, with the standard diet+water+LPS group displaying higher inflammatory responses in comparison to the other groups. Regarding standard diet groups treated with $L$. barbarum (standard diet + L. barbarum and standard diet + L. barbarum + LPS), both presented a significant decrease in inflammation when compared to the standard diet + water + LPS group $(p \leq 0.01)$. Likewise, a significant reduction $(p \leq 0.01)$ in the inflammatory response was observed in the palatable diet $+L$. barbarum group when compared to the palatable diet + water group. In addition, an increase in the inflammatory response in the palatable diet group was observed when compared to the standard diet group. 


\section{Inflammatory responses}

Inflammatory responses were also assessed by haptoglobin determinations (Figure 3), an acute phase protein (alpha 2-glycoprotein) produced in the liver. No significant differences $(p \geq 0.05)$ were observed among groups for this parameter.

\section{Serum transaminases}

Glutamic-oxaloacetic transaminase (Figure 4A) and glutamic-pyruvic transaminase (Figure 4B) were also analyzed for possible LPS- and palatable diet-induced liver damage. Glutamic-oxaloacetic transaminase was lower than the reference recommended in the literature [26], although a significant decrease $(\leq 0.05)$ of this parameter was observed when the standard diet $+L$. barbarum + LPS group was analyzed in relation to the control group (standard diet + water). Similarly, a significant reduction in the palatable diet $+L$. barbarum group when compared to the palatable diet + water group was observed, thus indicating that increased glutamic-oxaloacetic transaminase is possibly influenced by the presence of a high lipid diet. However, glutamic-pyruvic transaminase levels were higher than those recommended in the literature (GOT $=67.67$ $\mathrm{IU} / \mathrm{L}$ and $\mathrm{GPT}=27.56 \mathrm{IU} / \mathrm{L})$ [26], although, no significant difference $(\mathrm{p} \geq 0.05)$ was observed among the analyzed groups.

\section{Creatinine}

Creatinine was determined in order to assess possible renal function alterations (Figure 5). All experimental groups presented normal reference level for rats $\left(0.96 \mathrm{mg} \mathrm{dL}^{-1}\right)$, with the exception of the standard diet + water + LPS group which was observed a significant increase $(p \leq 0.01)$ when compared to the standard diet + L. barbarum + LPS group and standard diet + L. barbarum groups.

\section{Gene expression}

Gene expression of the inflammatory markers genes TNF- $\alpha$ and IL- 6 in liver were also assessed concerning dietary $L$. barbarum extract administration (Figure 6). A significant increase $(p<0.01)$ in TNF- $\alpha$ and IL- 6 genes observed between in the liver was observed in the group treated with standard diet $+L$. barbarum + LPS when compared to the standard diet + LPS group. However, no significant differences were observed in the palatable diet groups.

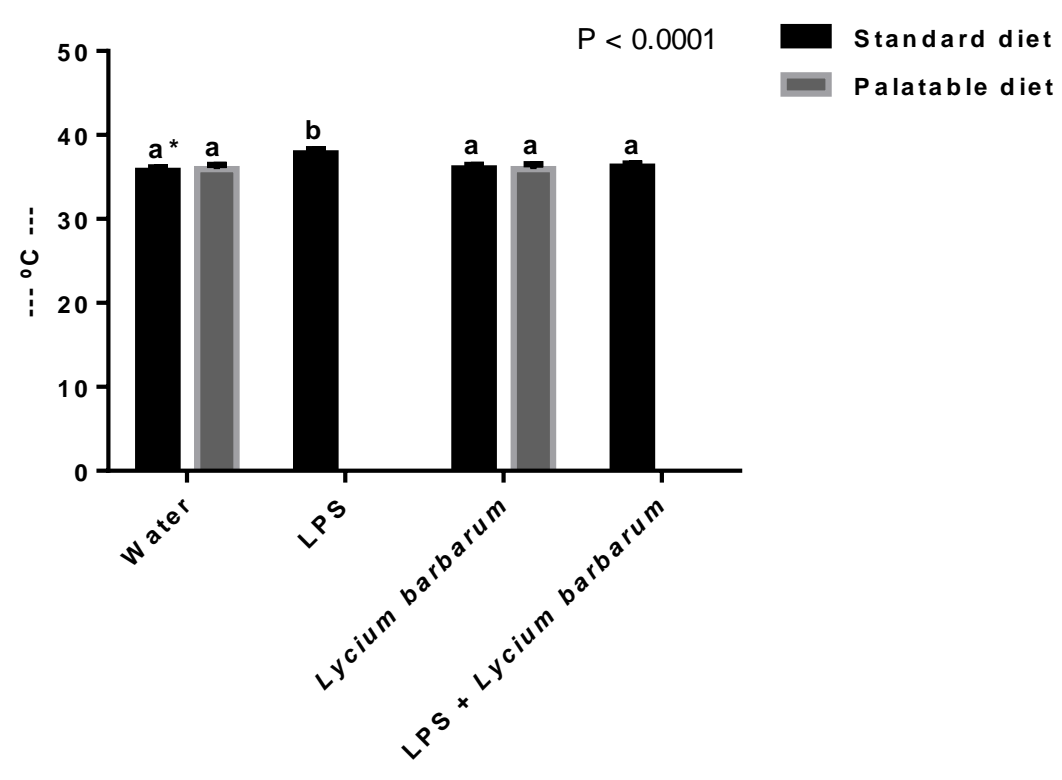

Figure 1. Rat body temperature obtained by a digital thermometer. Results are expressed as means \pm standard deviation. *Values with equal letters do not present significant difference between groups. 


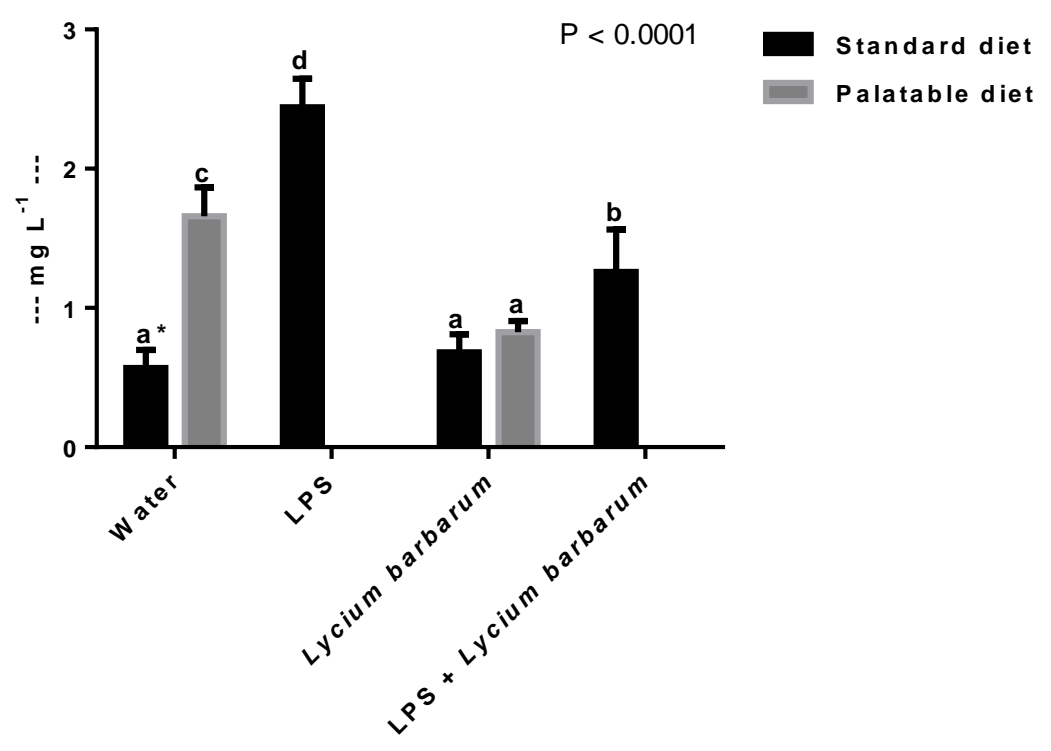

Figure 2. Determination of the anti-inflammatory protective effect of the Lycium barbarum extract by CRP analysis. Results are expressed as $\mathrm{mg} \mathrm{L}^{-1} .{ }^{*}$ Values with equal letters do not present significant difference between groups.

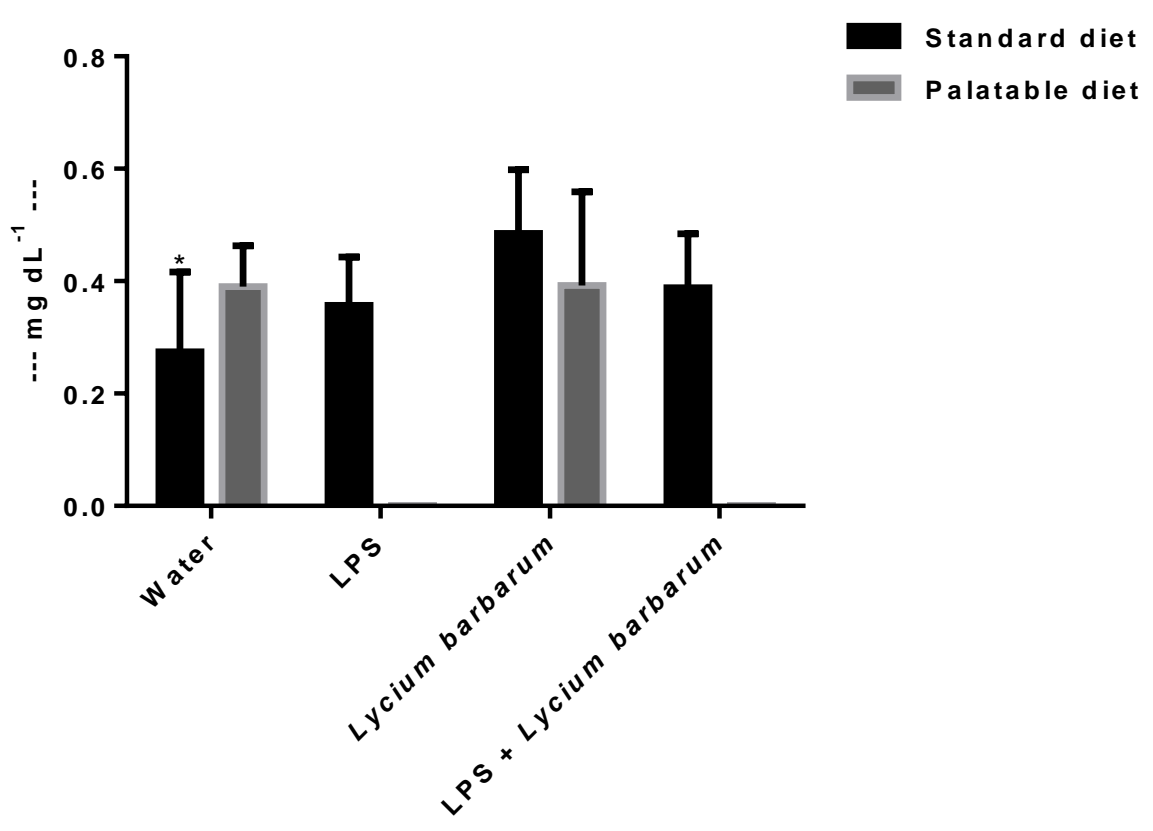

Figure 3. Determination of the protective anti-inflammatory effect of the Lycium barbarum extract by haptoglobin analysis. Results were expressed as $\mathrm{mg} \mathrm{dL}^{-1} .{ }^{*}$ The treatments showed no statistical significance. 


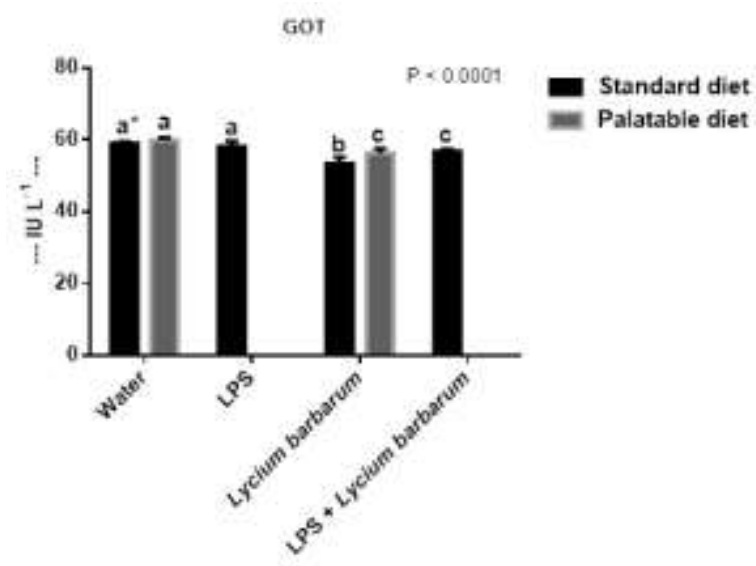

(a)

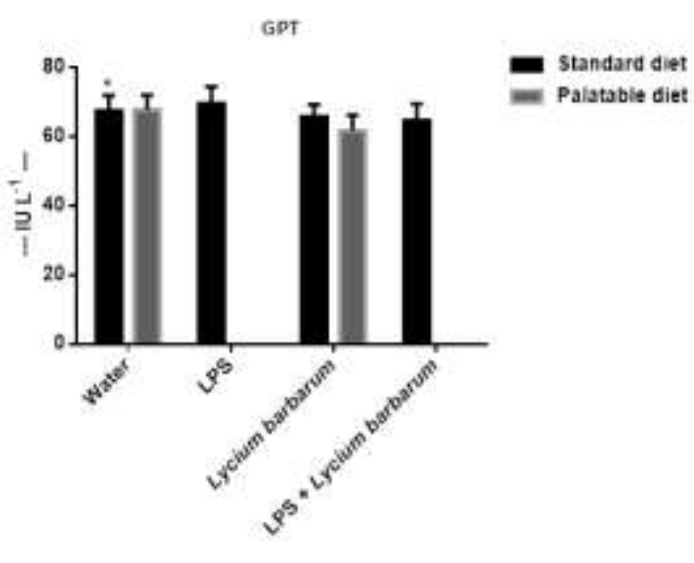

(b)

Figure 4. Determination of the anti-inflammatory effect of the Lycium barbarum extract on liver function assessed by glutamic-oxalacetic transaminase (GOT) and glutamic-pyruvic transaminase (GPT) analyses. Results are expressed in IU L-1. * Values with equal letters do not present significant difference between groups. * The Figure with no letters showed no statistical significance.

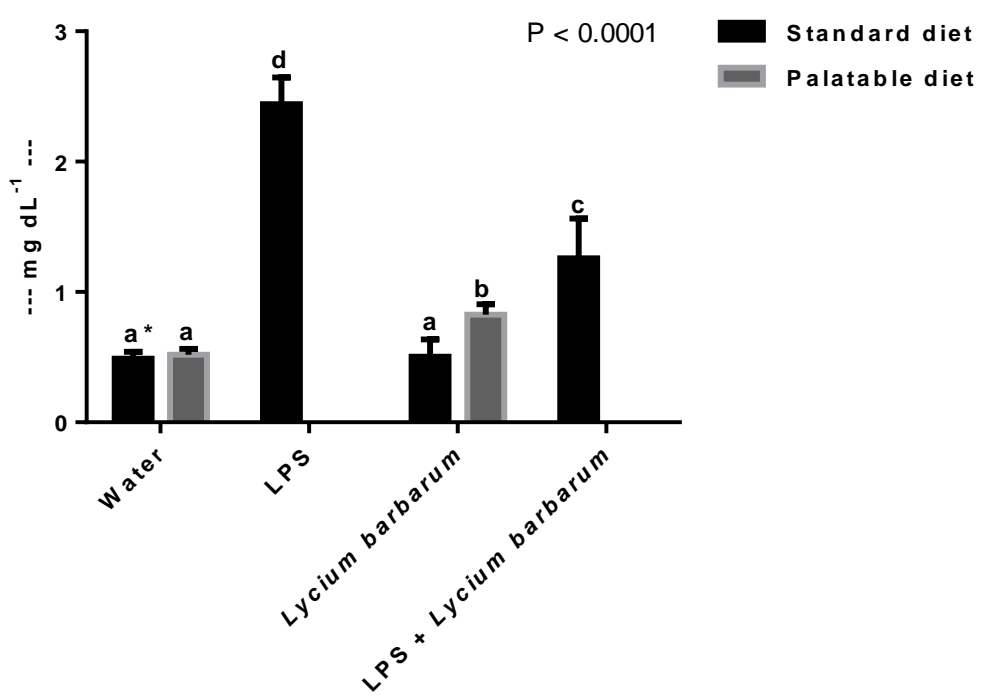

Figure 5. Determination of the anti-inflammatory effect of the Lycium barbarum extract on kidney function assessed by creatinine levels. Results were expressed in $\mathrm{mg} \mathrm{dL}^{-1} .{ }^{*}$ Values with equal letters do not present significant difference between groups. 


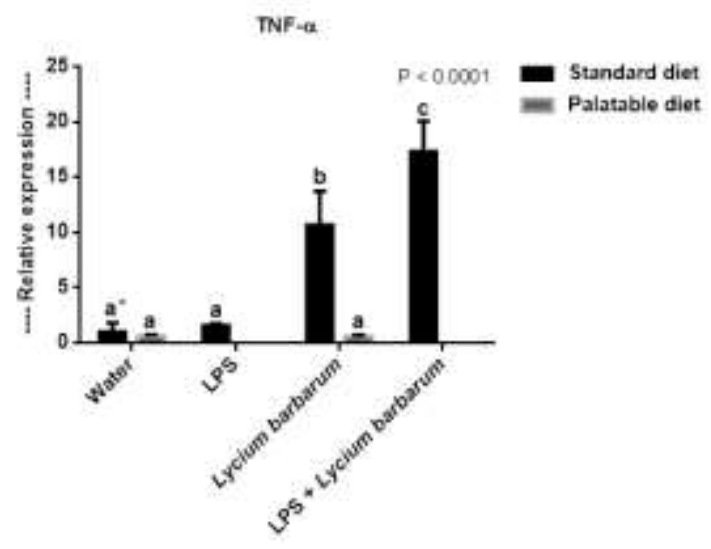

(a)

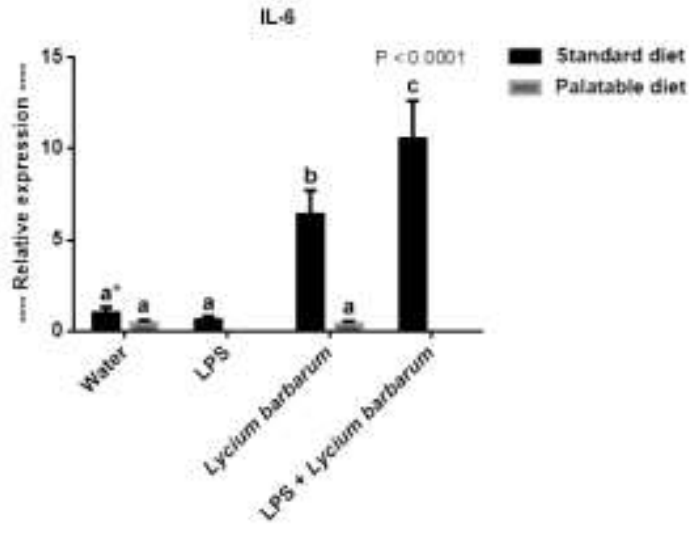

(b)

Figure 6. Relative expression levels of TNF- $\alpha$ and IL- 6 in liver of animals treated and not treated with Lycium barabarum.

*Values with equal letters do not present significant difference between groups.

Table 1. Primers used in the analysis of gene expression by real-time PCR.

\begin{tabular}{lccc}
\hline \multicolumn{1}{c}{ Primers } & Gene & Sequence $\left(5^{\prime}-3^{\prime}\right)$ & Length $(\mathrm{pb})$ \\
\hline Actb (forward) & $\beta$-actin & TCACCACCACAGCCGAGAGA & 72 \\
Actb (reverse) & CGAAATCCAGTGCGACGTAGC & \\
TNF- $\alpha$ (forward) & Tumor necrosis factor - alpha & ACAAGGCTGCCCCGACTAT & 585 \\
TNF- $\alpha$ (reverse) & & CTCCTGGTATGAAGTGGCAAATC & \\
IL-6 (forward) & Interleukin - 6 & GTCAACTCCATCTGCCCTTCAG & 538 \\
IL-6 (reverse) & & GGCAGTGGCTGTCAACAACAT & \\
\hline
\end{tabular}

\section{DISCUSSION}

Authors In this study the LPS was used as an inflammation inducer. This molecule is abundantly found in the outer membrane of gram-negative bacteria and is considered the main factor responsible for infection manifestations, involved in a variety of inflammatory disorders [28]. The results indicate that $L$. barbarum has the power to reduce LPS-induced inflammation. LPS-induced inflammation led to increased rat body temperature, and can be considered a defense mechanism against the inflammatory process, in order to combat the invading microorganism and reestablish physiological functions. L. barbarum administration led to decreased body temperature of up to $1.8^{\circ} \mathrm{C}$.

L. barbarum has been reported as a strong ally in the fight against infectious processes, due to its high amount of essential amino acids and anti-inflammatory properties [29]. A study carried out by Yang and coauthors [30] demonstrated that $L$. barbarum polysaccharide administration reduced ischemia-reperfusion injury in a mouse model, by suppressing oxidative stress and reducing inflammation.

In the present study, inflammatory responses were assessed by C-reactive protein levels, an acute phase protein produced by hepatocytes, synthesized by the liver and regulated by cytokines, predominantly IL-6, TNF- $\alpha$ and IL-1 [31]. The results indicate that the $L$. barbarum extract showed protective effect against LPS-induced inflammation. An increase in inflammatory responses was observed with administration of the hyperpalatable diet when compared to groups fed standard diets and therefore, decreased C-reactive protein levels in the palatable diet $+L$. barbarum group. It is possible that the increases in C-reactive protein levels in the hyperpalatable diet groups are the result of visceral adiposity, due to the inflammatory effects of abdominal obesity [32]. C-reactive protein increases rapidly in plasma in response to tissue injury, infection and inflammation [33] and in some specific conditions, such as obesity [34]. The results obtained in the present study corroborate data from the study carried out by Hogan and coauthors [35] who observed a significant increase in C-reactive protein levels after obesity induction in mice fed a diet containing $41 \%$ lipids for 12 weeks.

Possible liver damage induced by inflammation was noted using transaminases glutamic-oxaloacetic transaminase and glutamic-pyruvic transaminase data. The results obtained by glutamic-oxaloacetic 
transaminase showed that administration of $L$. barbarum can significantly reduce this parameter in both standard and palatable diets. Similarly, $L$. barbarum showed potential to reduce of this ezyme levels when administered LPS in the standard diet groups.

Matsuzaki and coauthors [36] observed a significant increase in glutamic-oxaloacetic transaminase and glutamic-pyruvic transaminase activity in the control group, when examined as non-specific and specific markers in the liver injury in mice receiving LPS administration. In contrast, the group undergoing caloric restriction (40\%) with LPS induction after 6 hours of administration, presented significantly reduced activity in relation to the control group.

Glutamic-oxaloacetic transaminase is widely distributed in animal and human tissues, and its major activity is found in the heart and skeletal muscles, as well as brain, liver and kidney [37]. It should be emphasized, therefore, that this is not a specific enzyme for liver injury, since any change in the aforementioned tissues may lead to enzymatic alterations.

The glutamic-pyruvic transaminase levels found in the present study were higher than reference values [26], although not significantly ( $p \geq 0.05)$, indicating that high levels of this parameter are found in the liver and can be considered a specific marker of liver damage. For Rochling [38], transaminases are elevated in the presence of certain pathologies, such as acute and chronic hepatitis, cirrhosis, hepatic congestion, infiltrative diseases such as infections or cancer. According to Cheng and Kong [39], L. barbarum significantly improved hepatic injury, preventing the progression of alcohol-induced liver fat accumulation, improving liver antioxidant function. Xiao and coauthors [40] report that $L$. barbarum protected the liver in rats presenting oxidative stress induced by carbon tetrachloride and inflammatory reactions.

In order to evaluate possible renal function alterations, a creatinine analysis was performed, and all groups presented normal reference creatinine values [26]. However, a significant increase $(p \leq 0.01)$ in the standard diet + water + LPS group was observed in relation to the standard diet + water; standard diet $+L$. barbarum + LPS, standard diet + L. barbarum and palatable diet + L. barbarum groups. Thus, $L$. barbarum seems to display a protective effect concerning creatinine levels. However, inferring that normal plasma creatinine values always indicate normal renal function may lead to important misunderstandings, since initial changes in the glomerular filtration rate may be "hidden" in normal creatinine values [41].

The expression of inflammatory marker genes TNF- $\alpha$ and IL-6 were also assessed, and a significant increase $(p<0.01)$ was observed in both genes in the standard diet + L. barbarum + LPS group. LPS, as the major active component of the cell wall in Gram-negative bacteria, can be recognized by the toll-like receptor 4 (TLR4) receptor complex and activate signal pathways to induce cytokine production, resulting in an inflammatory response [42, 43, 44]. IL-6, on the other hand, mediates a wide range of inflammatory and immune responses, while TNF- $\alpha$ displays a myriad of pro-inflammatory effects [45]. Pro-inflammatory cytokines such as TNF- $\alpha$ and IL- 6 are essential in activating the innate host defense system and subsequently modulating adaptive immune responses [46]. Thus, these results indicate that $\mathrm{L}$. barbarum may lead to the relief of inflammatory responses by down regulating inflammatory cytokine expression [44].

\section{CONCLUSION}

Based on the results obtained herein, the assessed $L$. barbarum extract presented the potential to reduce inflammatory responses, as C-protein reactive, glutamic-oxaloacetic transaminase and creatinine analyses. L. barbarum provided protection against LPS-induced inflammatory responses, protecting animals against systemic inflammation, liver damage and renal function alterations. In addition, the $L$. barbarum extract significantly reduced the inflammatory response induced by the palatable diet. It should be noted that $L$. barbarum also increased the expression of genes related to inflammatory response (TNF- $\alpha$ and IL-6), indicating that this fruit can exert immunomodulation functions by regulating inflammatory cytokine expression.

Funding: This study was financed in part by the Coordenação de Aperfeiçoamento de Pessoal de Nível Superior Brasil (CAPES) - Finance Code 001. Authors thank also the financial support of the Brazilian agencies: Conselho Nacional de Desenvolvimento Científico e Tecnológico - Brasil (CNPq) and Fundação de Amparo à Pesquisa do Estado do Rio Grande do Sul - Brasil (FAPERGS).

Conflicts of Interest: The authors declare no conflict of interest.

\section{REFERENCES}

1. Trischler J, Schubert R. Lipopolysaccharide challenge: immunological effects and safety in humans. J Expert Rev Clin Immunol.2015;11:409-18. 
2. Tsay TB, Yang MC, Sun JT, Chen PH, Lin YS, Shih MH, Chen LW. Enteric bacterial loads are associated with interleukin-6 levels in systemic inflammatory response syndrome patients. Formos J Surg. 2016;49:208-16.

3. Saluk-Juszczak J, Wachowicz B. The proinflammatory activity of lipopolysaccharide. Postepy Biochem.2005;51:2807.

4. Carswell EA, Old LJ, Kassel RL, Green S, Fiore N, Williamson B. An endotoxin-induced serum factor that causes necrosis of tumor. Proc Nat Acad Sci. 1975;72:3666-70.

5. Matsubara T, Ichiyama T, Furukawa S. Immunological profile of peripheral blood lymphocytes and monocytes/macrophages in Kawasaki disease. J Clin Exp Immunol. 2005;141:381-7.

6. Horssen RV, Hagen TLMT, Eggermont AMM. TNF- $\alpha$ in Cancer Treatment: Molecular Insights, Antitumor Effects, and Clinical Utility. The Oncologist. 2006;11:397-408.

7. Baydemir G, Bettazzi F, Palchetti I, Voccia D. Strategies for the development of an electrochemical bioassay for TNF-alpha detection by using a non-immunoglobulin bioreceptor. Talanta. 2016;151:141-7.

8. Osta B, Benedetti G, Miossec P. Classical and paradoxical effects of TNF-a on bone homeostasis. Front Immunol. 2014;48:1-9.

9. Ataie-Kachoie P, Pourgholami MH, Richardson DR, Morris DL. Gene of the month: Interleukin 6 (IL-6). J Clin Pathol. 2014;67:932-7.

10. Hartman J, Frishman WH. Inflammation and Atherosclerosis: A Review of the Role of Interleukin-6 in the Development of Atherosclerosis and the Potential for Targeted Drug Therapy. Cardiol Rev. 2014;22:147-51.

11.Scheller J, Chalaris A, Schmidt-Arras D, Rose-John S. The pro- and anti-inflammatory properties of the cytokine interleukin-6. Biochim Biophys Acta.2011;1813:878-88.

12.Szkandera J, Stotz M, Absenger G, Stojakovic T, Samonigg H, Kornprat P, Schaberl-Moser R, AlZoughbi W, Lackner C, Ress AL, Seggewies FS, Gerger A, Hoefler G, Pichler M. Validation of C-reactive protein levels as a prognostic indicator for survival in a large cohort of pancreatic cancer patients. British J Cancer.2014;110:183-8.

13. Windgassen EB, Funtowicz L, Lunsford TN, Harris LA, Mulvagh SL. C-reactive protein and high-sensitivity C-reactive protein: an update for clinicians. Postgrad Med.2011;123(1):114-9.

14.Perumal J, Balasundaram G, Mahyuddin AP, Choolani M, Olivo M. SERS-based quantitative detection of ovarian cancer prognostic factor haptoglobin. Int J Nanomedic.2015;10:1831-40.

15.Straat M, Van Bruggen R, Korte D, Juffermans NP. Red blood cell clearance in inflammation. Transfus Med Hemother.2012;39:353-61.

16. Hermsdorff HH, Zulet MA, Puchau B, Martínez JA. Central adiposity rather than total adiposity measurements are specifically involved in the inflammatory status from healthy young adults. Inflammation.2011;34:161-70.

17. Dandona P, Aljada A, Chaudhuri A, Mohanty P, Garg R. Metabolic syndrome: a comprehensive perspective based on interactions between obesity, diabetes, and inflammation. Circulation.2005;111:1448-54.

18.Chen JH, Tipoe GL, Liong EC, So HS, Leung KM, Tom WM, et al. Green tea polyphenols prevent toxin-induced hepatotoxicity in mice by down-regulating inducible nitric oxide-derived prooxidants. Am J Clin Nutr.2004;80:742-51.

19. Yang X, Bai H, Cai W, Li J, Zhou Q, Wang Y, Han J, Zhu X, Dong M, Hu D. Lycium barbarum polysaccharides reduce intestinal ischemia/reperfusion injuries in rats. Chem-Biol Interact.2013;204:166-72.

20.Cheng J, Zhou ZW, Sheng HP, He LJ, Fan XW, He ZX, Sun T, Zhang X, Zhao RJ, Gu L, Cao C, Zhou SF. An evidence-based update on the pharmacological activities and possible molecular targets of Lycium barbarum polysaccharides. Drug Des Devel Ther.2014;9:33-78.

21.Xing X, Liu F, Xiao J and So KF. Neuro-protective mechanisms of Lycium barbarum. Neuromolecular Med.2016;18:253-63.

22. Qian D, Zhao Y, Yang G and Huang L. Systematic review of chemical constituents in the genus Lycium (Solanaceae). Molecules. 22: pii: E911, 2017.

23.Souza CG, Moreira JD, Siqueira IR, Pereira AG, Rieger DK, Souza DO, Souza TM, Portela LV, Perry ML. Highly palatable diet consumption increases protein oxidation in rat frontal cortex and anxiety-like behavior. Life Sci.2007;81:198-203.

24. Liuzzo G, Biasucci LM, Gallimore JR, Grillo RL, Rebuzzi AG, Pepys MB, Maseri A. The prognostic value of C-reactive protein and serum amyloid a protein in severe unstable angina. N Engl J Med.1994;331:417-24.

25.Jones GE, Mould DL. Adaptation of the guaiacol (peroxidase) test for haptoglobins to a microtritation plate system. Res Vet Sci.1984;37:87-92.

26. Alemán CL, Más RM, Rodeiro I, Noa M, Hernández C, Menéndez R, Gámez R. Reference database of the main physiological parameters in Sprague-Dawley rats from 6 to 32 months. Lab Anim.1998;32:457-66.

27. Masternak MM, Al-Regaiey KA, Del Rosario Lim MM, Bonkowski MS, Panici JA, Przybylski GK, Bartke A. Caloric restriction results in decreased expression of peroxisome proliferator-activated receptor superfamily in muscle of normal and long-lived growth hormone receptor/binding protein knockout mice. J Gerontol.2005;60:1238-45. 
28.Kim HJ, Jeong JS, Kim SR, Park SY, Chae HJ, Lee YC. Inhibition of endoplasmic reticulum stress alleviates lipopolysaccharide-induced lung inflammation through modulation of NF-kB/HIF-1a signaling pathway. Sci Rep.2013;3:1142.

29. Luo Q, Lia Z, Huanga X, Yana J, Zhangb S, Caia YZ. Lycium barbarum polysaccharides: Protective effects against heat-induced damage of rat testes and $\mathrm{H} 2 \mathrm{O} 2$-induced DNA damage in mouse testicular cells and beneficial effect on sexual behavior and reproductive function of hemicastrated rats. Life Sci.2006;79:613-21.

30. Yang X, Bai H, Cai W, Li J, Zhou Q, Wang Y, Han J, Zhu X, Dong M, Hu D. Lycium barbarum polysaccharides reduce intestinal ischemia/reperfusion injuries in rats. Chem Biol Interact.2013;204:166-72.

31.Abdellaoui A, Al-Khaffaf $\mathrm{H}$. C-reactive protein (CRP) as a marker in peripheral vascular disease. Eur $\mathrm{J}$ Vasc Endovasc.2007;20:1-5.

32. Ozias MK, Li S, Hull HR, Brooks WM, Petroff MG, Carlson SE. Abdominal visceral adiposity influences CD4+ T cell cytokine production in pregnancy. Cytokine.2015;71:405-08.

33.Snodgrass JJ, Leonard WR, Tarskaia LA, McDade TW, Sorensen MV, Alekseev VP, et al. Anthropometric correlates of C-reactive protein among indigenous Siberians. J Physiol Anthropol.2007;26:241-6.

34.Nguyen XM, Lane J, Smith BR, Nguyen NT. Changes in inflammatory biomarkers across weight classes in a representative US population: a link between obesity and inflammation. J Gastrointest Surg.2009;13:1205-12.

35. Hogan S, Canning C, Sun S, Sun X, Kadouh H, Zhou K. Dietary supplementation of grape skin extract improves glycemia and inflammation in diet induced obese mice fed a western high fat diet. J Agr Food Chem.2011;59:303541.

36. Matsuzaki J, Kuwamura M, Yamaji R, Inui H, Nakano Y. Inflammatory responses to lipopolysaccharide are suppressed in 40\% energy-restricted mice. J Nutr.2001;131:2139-44.

37. Wróblewski $F$, Jervis G, Ladue JS. the diagnostic, prognostic and epidemiologic significance of serum glutamic oxaloacetic transaminase (sgo-t) alterations in acute hepatitis. Ann Intern Med.1956;45:782-800.

38. Rochling FA. Evaluation of abnormal liver tests. Clin Cornerstone.2001;3:1-12.

39. Cheng $\mathrm{D}$, Kong $\mathrm{H}$. The effect of Lycium barbarum polysaccharide on alcoholinduced oxidative stress in rats. Molecules.2011;16:2542-50.

40. Xiao J, Liong EC, Ching YP, Chang RC, So KF, Fung ML, Tipoe, GL. Lycium barbarum polysaccharides protect mice liver from carbon tetrachlorideinduced oxidative stress and necroinflammation. J Ethnopharmacol.2012;139:462-70.

41.Duncan L, Heathcote J, Djurdjev O, Levin A. Screening for renal disease using serum creatinine: who are we missing? Nephrol Dial Transpl.2001;16:1042-1046.

42.Kawai T, Akira S. TLR signaling. Semin Immunol.2007;19:24-32.

43. Newton K, Dixit VM. Signaling in innate immunity and inflammation. Cold Spring Harb Perspect Biol.2012;4:1-19.

44. Liu YL, Yin RQ, Liang SS, Duan YL, Yao JH, Yang XJ. Effect of dietary Lycium barbarum polysaccharide on growth performance and immune function of broilers. J Appl Poult Res.2017;26:200-8.

45.Xi L, Wang C, Chen P, Yang Q, Hu R, Zhang H, Weng Q, Xu M. Expressions of IL-6, TNF- $\alpha$ and NF-kB in the skin of Chinese brown frog (Rana dybowskil). Eur J Histochem.2017;61:2834,264-9.

46. Wang X, Shen J, Li S, Zhi L, Yang X, Yao J. Sulfated Astragalus polysaccharide regulates the inflammatory reaction in LPS-infected broiler chicks. Int J Biol Macromol.2014;69:146-50.

(C) 2020 by the authors. Submitted for possible open access publication under the terms and conditions of the Creative Commons Attribution (CC BY NC) license (https://creativecommons.org/licenses/by-nc/4.0/). 